After surgical incision the expected (Carter and James, 1970) rise of plasma corticosteroid concentration occurred in those patients receiving general anaesthetic alone, but epidural block modified this response. Where the epidural block lasted only for the operative period the plasma corticosteroid concentration rose rapidly after surgery. Prolonged epidural block suppressed the rise so long as the block remained effective.

Previous studies on the effect of spinal anaesthesia on the adrenocortical response to surgery (Sandberg et al., 1954); Johnston, 1964) have shown inconsistent results. During spinal block these patients remained conscious and the hypothalamicpituitary-adrenal axis may be stimulated by mechanisms which include emotional stimuli and which would not be affected by spinal anaesthesia.

High transection of the spinal cord prevents the normal adrenocortical response to surgery (Hume et al., 1962). It is tempting to suggest that the adrenocortical response to trauma is mediated by nervous reflex linking the operation site with the central nervous system. In unconscious patients our finding was that the adrenocortical response was suppressed when the nervous pathways from the operation site were interrupted by epidural block.

Epidural and spinal block do not always produce total anaesthesia, and this may account for individual variations of corticosteroid response (fig. 2). Despite evidence of incomplete epidural blockade in case 1 and a similar case in group B, these two cases were not excluded from the series, although their omission might have increased the significant difference between group $A$ and groups $B$ and $C$. The other patient (case 2, fig. 2) may represent the effect of what was clinically complete epidural blockade. The absence of a rise in plasma corticosteroid concentration had no apparent effect on the reaction to major surgery in this patient, and her recovery was uneventful.

"Collapse" complicating surgery in patients receiving corticosteroid therapy has been recorded repeatedly over the last 20 years (Fraser et al., 1952). For this reason steroid cover for surgery has become routine (Bayliss, 1958) for all patients who have received corticosteroid therapy in the preceding two years. Close examination of the reports of collapse attributed to adrenocortical failure shows the relation to be based on circumstantial evidence (Cope, 1966). The first case report of collapse during surgery associated with a low adrenocortical steroid concentration (Sampson et al., 1961) responded to the intravenous administration of hydrocortisone. However, this therapy achieved steroid concentrations twice those normally found in response to surgery. The clinical improvement may have been similar to that seen in shocked patients treated with hydrocortisone who have normal adrenocortical function (Marks et al., 1959). Study of both medical and surgical patients with arterial hypotension due to suspected adrenocortical failure (Mattingly and Tyler, 1965) showed raised plasma corticosteroid concentrations in all 47 cases.

More recently modification to the prophylactic regimens has been suggested and, indeed, the necessity for cover in patients who have stopped corticosteroid therapy before surgery has been questioned (Plumpton et al., 1969). An adequate adrenocortical response to surgery was found in these patients.

In our patients in whom the expected adrenocortical response was inhibited by epidural block it was found that a low plasma corticosteroid concentration was not detrimental per se, was not associated with cardiovascular collapse during or after surgery, and it had no apparent effect on recovery from either anaesthesia or surgery.

The administration of supplementary corticosteroid drugs for the stress of surgery remains an open question.

We wish to thank Professor R. J. Kellar for allowing us to investigate his patients, and the department of medical illustrations, Edinburgh University, for their help.

\section{References}

Bayliss, R. I. S. (1958). British Medical Fournal, 2, 935.

Black, S., and Friedman, M. (1968). British Medical fournal, 1, 477.

Black, S., and Friedman, M. (1968). British Medical four

Carter, M. E., and James, V. H. (1970). Lancet, 1, 328

Fraser, C. G., Preuss, F. S., and Bigford, W. D. (1952). Fournal of the American Medical Association, 149, 1542.

Hume, D. M., Bull, C. C., and Bartter, F. (1962). Surgery, 52, 174.

Ichikawa, Y. Kawagoe, M., Nishikai, M., Yoshida, K. and Homma, M. (1971). Fournal of Laboratory and Clinical Medicine, 78, 882.

Johnston, I. D. A. (1964). Annals of the Royal College of Surgeons of England, 35, 270.

Marks, L. J., Donovan, M. J., Duncan, F., and Karger, R. (1959). Fournal of Clinical Endocrinology and Metabolism, 19, 1458.

Mattingly, D. (1962). Fournal of Clinical Pathology, 15, 374.

Mattingly, D., and Tyler, C. (1965). Proceedings of the Royal Society of Medicine, 58,1010 .

Oyama, T. et al. (1968). Anesthesiology, 29, 559

Plumpton, F. S., Besser, G. M., and Cole, P. V. (1969). Anaesthesia, 24, 3. Sampson, P. A., Brooke, B. N., and Winstone, N. E. (1961). Lancet, 1, 1377. Sandberg, A. A., Eiknes, K., Samuels, L. T., and Tyler, F. H. (1954) Fournal of Clinical Investigation, 33, 1509.

Fournal of Clinical Investigation, 33, 1509. British fournal of Anaesthesia,
Utting, J. E., and Whitford, J. H. W. (1972). Brite 44, 43.

\title{
Facial Sweating after Food: A New Sign of Diabetic Autonomic Neuropathy
}

\author{
P. J. WATKINS
}

British Medical fournal, 1973, 1, 583-587

\section{Summary}

Facial sweating during eating (gustatory sweating) has been observed for the first time in a group of diabetics, and is considered to be a feature of the autonomic neuropathy which affected them all. The sweating, which was sometimes very severe, was produced by

King's College Hospital, London SE5 9RS

P. J. WATKINS, M.D., M.R.C.P., Consultant Physician many foodstuffs, cheese being the most powerful stimulus. Atropine inhibited sweating stimulated by eating cheese, and oral anticholinergic drugs effectively eliminated the symptoms. These bizarre symptoms are probably due to abnormal nerve regeneration occurring as a consequence of the spontaneous autonomic neuropathy.

\section{Introduction}

Facial sweating during eating (gustatory sweating) is a normal response to highly spiced foods (Lee, 1954) and also occurs as an idiosyncrasy in some individuals, especially after chocolate 
or cheese. At a meeting of the Paris Biological Society in 1849 Brown-Séquard described and demonstrated the severe facial sweating which enveloped him within minutes after eating chocolate. Gustatory sweating generally follows nerve damage and is thought to be due to aberrant regeneration of nerve fibres. The best known form is the auriculotemporal or Frey's syndrome, in which sweating (and flushing) occurs in the distribution of the auriculotemporal nerve as a result of damage in its course through the parotid gland (Parkes Weber, 1947; Monro, 1959). Localized areas of gustatory sweating have been described after nerve damage in the submental region (Young, 1956), over the left side of the neck and shoulder after thoracotomy (Herxheimer, 1958), and in a case of syringomyelia (Wilson, 1936). Cervical sympathectomy may also result in gustatory sweating starting some weeks or even years after the operation (List and Peet, 1938; Haxton, 1948; Bloor, 1966; Greenhalgh et al., 1971).

Spontaneous degeneration of autonomic nerves in diabetics sometimes occurs in association with established peripheral neuropathy (Rundles, 1945; Keen, 1959), although the pathology of this condition has not been adequately described. Any effector organ which receives an autonomic innervation may be affected. Sweating abnormalities resulting in both increased and decreased perspiration are well known, but spontaneous gustatory sweating has not previously been described in diabetics. This paper describes six cases and discusses the relationship of the phenomenon with autonomic neuropathy.

\section{Patients and Observations}

Six patients were studied (see table). Two of them (cases 3 and 6) complained spontaneously of sweating after food, and one of these (case 3) was drenched with sweat at every meal. The remaining patients were discovered by asking many diabetics, usually with multiple complications, whether they experienced any disturbing symptoms at mealtimes.

\section{Findings}

All but one of the patients had been diagnosed at under 20 years of age, and all were on insulin. Their diabetes had been present for 18 to 29 years at the time of the observations, and all had had gustatory sweating symptoms for several years. They all suffered from severe diabetic complications. All six had advanced retinopathy (only one had good vision), and five had nephropathy evidenced by proteinuria, two being in chronic renal failure. Peripheral neuropathy was present in all the patients. All six had absent ankle jerks, and numbness of the feet or neuritic pains were present in five. In cases 1 and 2 multiple foot operations had been performed for recurrent sepsis. These two patients also had severe upper limb neuropathy leading to impaired sensation in the fingers, with consequent cigarette burns, and wasting of the small muscles of the hands; elbow wrist conduction times were markedly reduced (right median
$40 \mathrm{~m} / \mathrm{sec}$ in both cases, and right ulnar 35 and $36 \mathrm{~m} / \mathrm{sec}$ respectively; normals usually exceed $50 \mathrm{~m} / \mathrm{sec}$ ).

All the patients had many features of autonomic neuropathy (see table), including diarrhoea, impotence, and excessive sweating of the trunk at night (cases 3 and 5); postural hypotension (a fall in systolic pressure of more than $30 \mathrm{~mm} \mathrm{Hg}$ on standing) was present in three patients (cases 1,2, and 6). Pupil reactions were normal in three out of four patients and reaction to light was absent in only one (case 6); the remaining two patients were blind.

\section{SYMPTOMS}

Facial sweating usually appeared a few seconds after the patient started to chew food. Perspiration was first felt but soon became visible on the forehead, quickly spreading to involve most of the face (fig. 1), although the cheeks and tip of the nose were occasionally spared. The scalp was sometimes affected. Sweating spread to the throat and neck, and sometimes extended to the shoulders and upper part of the chest. The sweat generally streamed down the face, and in two patients was so severe that it poured down the chest (cases 1 and 3), making the shirt sodden at mealtimes. Two patients kept a towel at table to mop their faces (cases 1 and 2). The symptoms varied in their

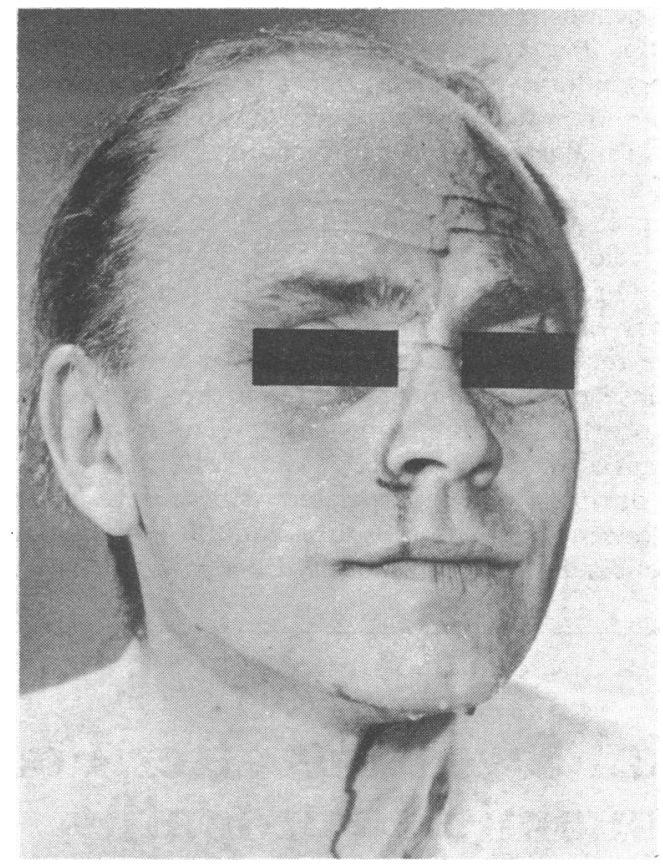

FIG. 1-Case 1. Severe facial sweating a few minutes after eating cheese. Quinizarin powder, which turns blue when moist, was placed on the left forehead and is shown running down the face and neck.

\begin{tabular}{|c|c|c|c|c|c|c|c|c|c|}
\hline Case No. & & Sex & $\begin{array}{c}\text { Age at } \\
\text { Diagnosis }\end{array}$ & $\begin{array}{c}\text { Duration of } \\
\text { Diabetes } \\
\text { (Years) }\end{array}$ & $\begin{array}{l}\text { Approx. } \\
\text { Duration of } \\
\text { Gustatory } \\
\text { Sweating } \\
\text { (Years) }\end{array}$ & $\begin{array}{l}\text { Diabetic } \\
\text { Diarrhoea }\end{array}$ & Impotence & Retinopathy & Proteinuria \\
\hline $\begin{array}{l}\cdots \\
\therefore \\
\cdots \\
\cdots \\
\cdots\end{array}$ & $\begin{array}{l}. \\
\because \\
\because \\
\therefore \\
\therefore\end{array}$ & $\begin{array}{l}\text { M. } \\
\text { M. } \\
\text { M. } \\
\text { M. } \\
\text { F. }\end{array}$ & $\begin{array}{l}12 \\
18 \\
18 \\
19 \\
15 \\
26\end{array}$ & $\begin{array}{l}29 \\
23 \\
18 \\
27 \\
21 \\
24\end{array}$ & $\begin{array}{c}9 \\
9 \\
5 \\
10 \\
8 \\
\text { "Many" }\end{array}$ & $\begin{array}{l}+ \\
+ \\
+ \\
+ \\
0 \\
0\end{array}$ & $\begin{array}{c}\text { R.E. } \\
+ \\
+ \\
+ \\
+ \\
+\end{array}$ & $\begin{array}{l}\text { R.P.* } \\
\text { R.P.* } \\
\text { R.P.* } \\
\text { R.P.ं } \\
\text { N.V. } \\
\text { R.P. }\end{array}$ & $\begin{array}{l}+ \\
+ \\
+t \\
+t \\
0 \\
+\end{array}$ \\
\hline
\end{tabular}

* Blind.

$\dagger$ Chronic renal failure.

R.E. = Retrograde ejaculation. R.P. = Retinitis proliferans. N.V. = Neovascularization. 
intensity on different occasions, but in cases 1 and 3 they were very persistent.

\section{DISTRIBUTION OF SWEATING}

Head, neck and shoulders, and upper part of the chest of all the patients were covered with quinizarin powder, which turns blue when moist (Guttmann, 1947). They were then asked to chew strong Cheddar cheese (Canadian Black Diamond),

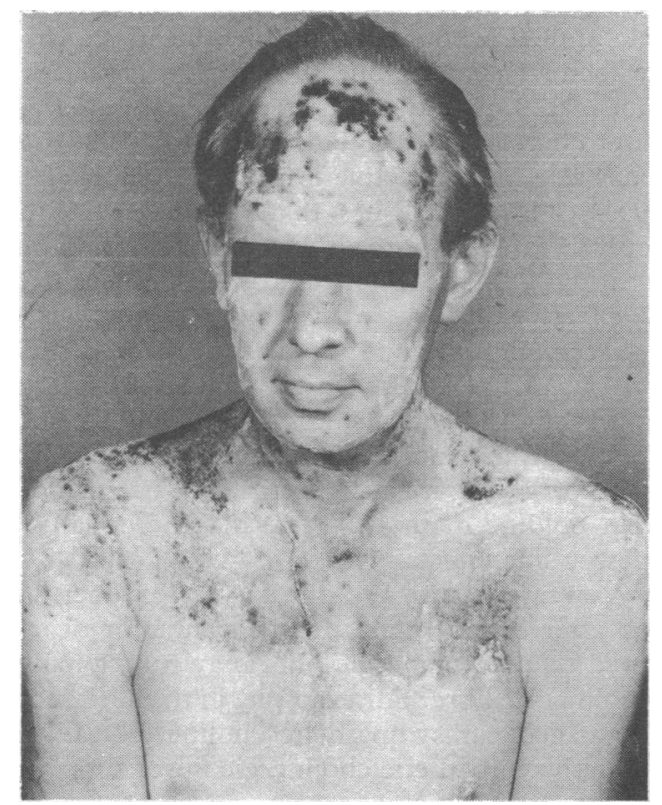

FIG. 2-Case 2. Area of sweating after eating cheese. Quinzarin powder clearly demarcates the affected parts. Sweating extends approximately to the fourth cervical dermatome.

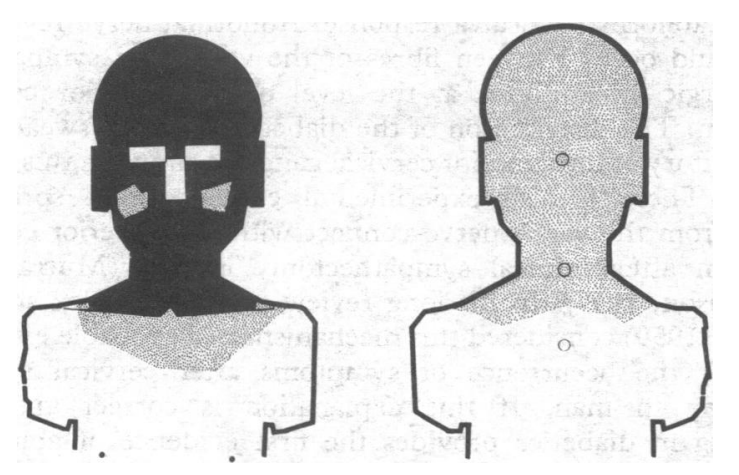

FIG. 3-Case 1. Area of sweating after eating cheese. Darker shading indicates heavier sweating, which extends down to the third cervical dermatome.

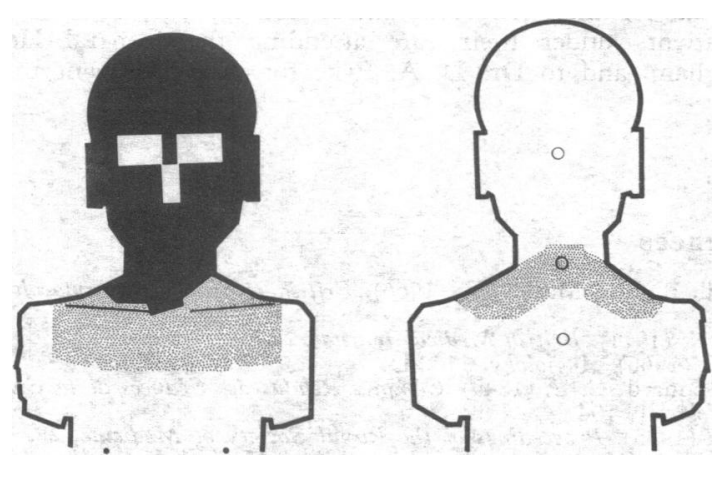

PIG. 4-Case 3. Area of sweating (down to fourth cervical dermatome) after eating cheese. and detailed photographs were taken to show the area of sweating. The example shown in fig. 2 indicates that these areas were clearly demarcated. The exact distribution of sweating in two of the patients is shown in figs. 3 and 4 . In four cases the level of sweating extended down to the region of the third or fourth cervical dermatomes, an area corresponding with that of the sympathetic supply from the superior cervical ganglion (Pick, 1970).

\section{STIMULI CAUSING GUSTATORY SWEATING}

Cheese was noted as a cause of facial sweating by all the patients and was the most potent stimulus in five. In some instances cheese was the only really troublesome foodstuff, and these patients preferred not to eat any on account of the inconvenience.

Other foodstuffs incriminated were pickles (three), alcohol, especially dry wine (three), fresh fruit (three), vinegar in mint sauce (two), salty foods (two), and bread and butter (two). Cases 1 and 3 were the most severely affected, and facial sweating occurred at almost every meal. In particular, case 3 was bathed in sweat after every snack and meal and was not able to identify any individual foodstuff as particularly offensive.

Cases 1 and 2 were examined in more detail. The act of chewing an inert substance (Parafilm) for several minutes did not cause sweating. Eating an orange or half a lemon caused only slight facial sweating, as did chocolate (case 1 only). Cheese caused severe sweating in both cases, and this occurred during chewing and before swallowing. A $90-\mathrm{mg}$ dose of tyramine, which is approximately the amount in $3 \mathrm{oz}(85 \mathrm{~g})$ of Cheddar cheese (Blackwell and Marley, 1966), was placed on the back of the tongue in both these patients without causing any sweating.

Three patients (cases 1,2 , and 4 ) were given atropine intravenously to a total dose of $1.8 \mathrm{mg}$ over three to five minutes. Chewing cheddar cheese then caused no sweating whatever. The expected dry mouth and dry eyes were also observed. Propantheline (Pro-Banthine) was therefore given to five of the patients; three (cases 1, 2, and 6) obtained striking relief, and case 5 also improved when the anticholinergic drug was changed to poldine methylsulphate (Nacton). All the patients suffered side effects, especially dry mouth and constipation, and most preferred not to take propantheline but rather to avoid provocative foodstuffs. One patient (case 6), however, noted that the propantheline made a great difference to her social life and found it a great relief to be able to dine without feeling as if she had been in "a Turkish bath from the neck upwards."

\section{INVESTIGATIONS OF AUTONOMIC FUNCTION}

Sweat Test.-Four patients were studied (cases 1, 2, 4, and 5) by body heating in order to detect areas of defective sweating, and abnormalities were found in all. Thus there was no sweating of the feet in any of them, and none below the knees in two. The fingers also remained dry in cases 1,2 , and 4. Sweating of the trunk was profuse (normal) in all the patients.

Heart Rate and Valsalva Manoeuvre. - A resting tachycardia of 100-110 beats a minute was noted in three cases (fig. 5), probably indicating a vagal defect of cardiac innervation. The Valsalva manoeuvre was performed with reference to heart rate only (Elisberg, 1963), and an abnormal response was elicited in all six patients (fig. 5). The expected increase in heart rate towards the end of the blowing phase of the test was seen in only three cases, and in the remainder there was no change in rate throughout. There was no reflex bradycardia after blowing in any of the patients.

Use of Atropine.-Intravenous atropine was given to three patients (cases 1, 2, and 4) to a total dose of $1.8 \mathrm{mg}$ (fig. 6). The expected increase in heart rate did not occur in any of the patients, and in one (case 2) there was no detectable increase in rate. Indeed, the heart rate in the latter case remained unaltered 


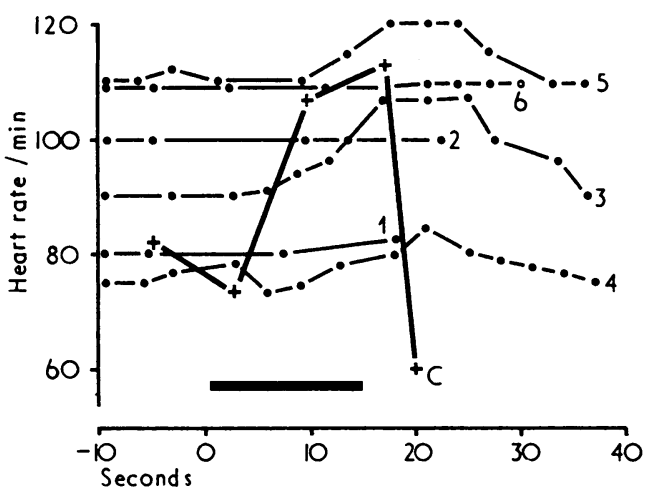

FIG. 5-Heart rates during Valsalva manoeuvre in the sig. cases. Horizontal bar indicates period of blowing a mercury column to $40-50 \mathrm{~mm} \mathrm{Hg}$. Line $C$ shows the result of control studies (Elisberg, 1963).

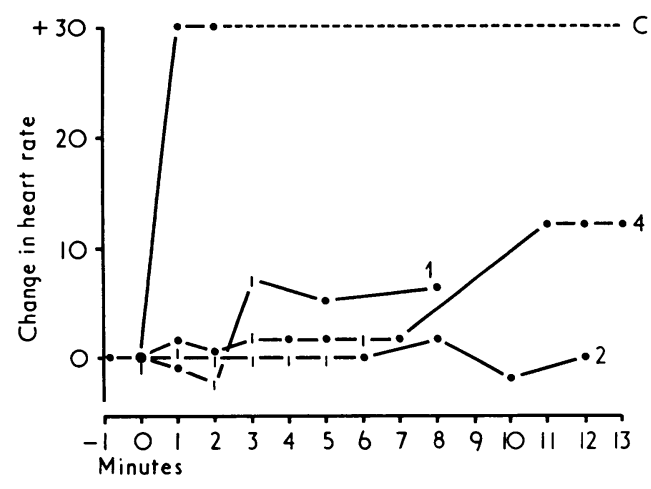

FIG. 6-Effect on heart rate of intravenous atropine. Injection was started at 0 and given in equally divided amounts at the times indicated by the vertical bars (1) to a total of $1.8 \mathrm{mg}$. C indicates average response (Elisberg et al., 1953) to a dose of $2.0 \mathrm{mg}$.

at $100 / \mathrm{min}$ throughout all the manoeuvres (resting, standing, Valsalva, and after atropine).

\section{Discussion}

Gustatory facial sweating as described in this group of diabetics is probably a manifestation of extensive autonomic neuropathy. Thedrenching facial sweats occurring at mealtimes in our patients were distressing to some and a social embarrassment to all. The symptoms appear a few seconds after starting to chew food, and although intermittent in some cases may occur with every meal or snack. The area of sweating is very precisely demarcated, extending as low as the level of the third or fourth cervical dermatome, but it is always restricted to the territory of the superior cervical ganglion. It is very similar to the gustatory sweating pattern noted after cervical sympathectomy (Greenhalgh et al., 1971).

The stimulus which provokes gustatory sweating is the chewing of tasty foodstuffs. Chewing an inert substance such as Parafilm (used here) or cotton wool does not lead to facial sweating (Uprus et al., 1934; List and Peet, 1938; Tankel, 1951). The most sensitive area of the mouth is the tongue (Lee, 1954). Cocainization of the mouth and tongue does not completely inhibit gustatory sweating, probably because it is difficult to anaesthetize the taste buds (List and Peet, 1938; Tankel, 1951). There is no evidence of oesophageal or gastric reflexes (Lee, 1954), and alcohol introduced direct into the stomach does not cause facial sweating (Tankel, 1951).

A wide variety of foodstuffs have been incriminated by most sufferers of gustatory sweating and have included cheese, chocolate, alcohol, pickles, and many others, especially acid, bitter, or spicy substances (Monro, 1959). Cheese and chocolate seem to be particularly troublesome in those with idiosyncratic symptoms (Brown-Séquard, 1849). Cheese is the most constantly described stimulus in most reported cases and was the most potent cause of symptoms in the present series. In one patient (case 1) even the thought of cheese was sufficiently distressing to cause slight facial sweating, and in others this may occur at the sight of spicy foods (List and Peet, 1938). Tyramine (which occurs in large amounts in some cheeses) did not cause facial sweating in the two diabetics tested here. It is suggested that these bizarre symptoms are a gustatory reflex response and not due to the absorption of any pharmacologically active substance. The observations are in contrast to the finding in migraine sufferers, in whom cheese and chocolate may provoke attacks (Blau, 1971) and in whom tyramine has been shown to be a responsible factor (Hannington, 1967).

Intravenous administration of atropine inhibited gustatory sweating after cheese in all three diabetics tested in the present study and has also been effective in other instances (Lee, 1954; Tankel, 1951). This establishes that cholinergic fibres which usually supply sweat glands are also responsible for this abnormal form of sweating. Orally administered anticholinergic drugs are apparently effective in cases occurring after cervical sympathectomy (Greenhalgh et al., 1971) and were used successfully here in four out of five cases. Unfortunately the effective dose also causes tiresome side effects, notably dry mouth and constipation, and several patients had to stop treatment. Other anticholinergic preparations are at present being tried, and it seems probable that poldine methylsulphate may be equally effective and cause fewer side effects.

Gustatory sweating may be the result of aberrant nerve regeneration after degeneration due to trauma or disease. Dale (1935) showed that a cholinergic fibre may functionally replace any other cholinergic fibre. For example, in the auriculotemporal syndrome damaged parasympathetic cholinergic salivary fibres may reunite with sympathetic cholinergic fibres supplying sweat glands (Gillilan, 1955).

The mechanism causing gustatory sweating in the diabetics described here may have been a consequence of the autonomic degenerative changes. These included abnormalities of vagal innervation of the heart evidenced by a resting tachycardia and an abnormal Valsalva response. Abnormal nerve regeneration could occur between fibres of the vagus and sympathetic cholinergic sweat fibres at the level of the superior cervical ganglion. The distribution of the diabetic gustatory sweating in the territory of the superior cervical ganglion supports this hypothesis. There is also experimental evidence that sprouting fibres from the vagus nerve connect with the superior cervical ganglion after cervical sympathectomy in cats (Murray and Thompson, 1957). In his long review of this complex subject, Monro (1959) considered this mechanism as a probable explanation for the occurrence of symptoms after cervical sympathectomy in man. If this explanation is correct gustatory sweating in diabetics provides the first evidence of abnormal nerve regeneration in patients with spontaneous autonomic neuropathy.

I am grateful to Professor J. M. Malins and Dr. M. G. FitzGerald for their help and advice and for permission to study four patients under their care attending the General Hospital, Birmingham, and to Dr. D. A. Pyke for encouragement throughout.

\section{References}

Blackwell, B., and Marley, E. (1966). British fournal of Pharmacology, 26, i 20.

Blau, J. N. (1971). British Medical fournal, 2, 751.

Bloor, K. (1966). Angiology, 17, 143.

Brown-Séquard, C.-E. (1849). Comptes Rendus des Séances de la Société de Biologie, 1, 104 .

Dale, H. (1935). Proceedings of the Royal Society of Medicine, 28, 319.

Elisberg, E. I. (1963). Fournal of the American Medical Association, 186, 200. Elisberg, E., Miller, G., Weinberg, S. L., and Katz, L. N. (1953). American Heart fournal, 45, 227. 
Gillilan, L. A. (1955). Clinical Aspects of the Autonomic Nervous System. London, Churchill.

Greenhalgh, R. M., Rosengarten, D. S., and Martin, P. (1971). British Medical fournal, $1,332$.

Guttmann, L. (1947). Postgraduate Medical fournal, 23, 353.

Hannington, E. (1967). British Medical fournal, 1, 550.

Haxton, H. A. (1948). Brain, 71, 16.

Herxheimer, A. (1958). British Medical fournal, 1, 688.

Keen, H. (1959). Postgraduate Medical Fournal, 35, 272.

Lee, T. S. (1954). Fournal of Physiology, 124, 528.

List, C. F., and Peet, M. M. (1938). Archives of Neurology and Psychiatry, 40,443 .
Monro, P. A. G. (1959). Sympathectomy. London, Oxford University Press. Murray, J. G., and Thompson, J. W. (1957). British Medical Bulletin, 13,

Parkes Weber, F. (1947). Rare Diseases and Some Debatable Subjects, 2nd edn. London, Staple Press.

Pick, J. (1970). The Autonomic Nervous System. Philadelphia, Lippincott. Rundles, R. W. (1945). Medicine, 24, 111.

Tankel, H. I. (1951). Fournal of Neurology, Neurosurgery and Psychiatry, 14, 129.

Uprus, V., Taylor, J. B., and Carmichael, E. A. (1934). Brain, 57, 443.

Wilson, W. C. (1936). Clinical Science, 2, 273.

Young, A. G. (1956). British Medical fournal, 2, 976.

\title{
Pharmacological Modification of Gastric Emptying: Effects of Propantheline and Metoclopromide on Paracetamol Absorption
}

\author{
J. NIMMO, R. C. HEADING, P. TOTHILL, L. F. PRESCOTT
}

British Medical fournal, 1973, 1, 587-589

\section{Summary}

The rate of paracetamol absorption depends on the rate of gastric emptying. Propantheline delayed gastric emptying and markedly slowed the absorption of paracetamol in six convalescent hospital patients. Conversely, the absorption of paracetamol in five healthy volunteers was accelerated by metoclopramide, a drug which stimulates gastric emptying. The total 24-hour urinary excretion of paracetamol was not influenced by propantheline or metoclopramide. Other similar absorption interactions probably occur since drugs are poorly absorbed from the stomach and many therapeutic agents influence gastrointestinal motility.

\section{Introduction}

Most drugs are absorbed from the gastrointestinal tract as unionized molecules by passive diffusion. Lipid solubility is an important factor and the rate of transfer is thought to depend on $\mathrm{pH}$ since this determines the fraction of drug present in the unionized lipid soluble state. It is said that weakly acidic drugs are readily absorbed from the acid contents of the stomach while weakly basic drugs are poorly absorbed from this site but are rapidly absorbed from the more alkaline environment of the upper small intestine (Hogben et al., 1957; Schanker et al., 1957; Brodie, 1964). More recent studies have shown, however, that acidic drugs such as warfarin, acetylsalicylic acid, and phenobarbitone are absorbed much more slowly from the stomach than from the small intestine, presumably because the latter has a much larger relative surface area (Siurala et al., 1969; Kekki et al., 1971; Kojima et al., 1971). Contrary to general belief, even easily diffusible neutral compounds of low molecular weight such as ethanol are absorbed more slowly from the stomach than from the small intestine (Magnussen, 1968).

\footnotetext{
University Departments of Therapeutics and Medical Physics, The Royal Infirmary, Edinburgh EH3 9YW

J. NIMMO, B.SC., M.R.C.P., Lecturer in Clinical Pharmacology

R. C. HEADING, B.SC., M.R.C.P., Lecturer in Therapeutics

P. TOTHILL, PH.D., Senior Lecturer in Medical Physics

L. F. PRESCOTT, M.D., F.R.C.P., Senior Lecturer in Clinical Pharmacology
}

The rate of gastric emptying is therefore likely to have important effects on the rate of drug absorption, and in previous studies we have shown that paracetamol absorption in man is related to the rate of gastric emptying (Heading et al., 1973). Propantheline and metoclopramide delay and accelerate gastric emptying respectively, and their influence on the absorption of paracetamol is described in the present report.

\section{Subjects and Methods}

Paracetamol absorption was studied before and after metoclopramide in five healthy ambulant male volunteers aged from 22 to 39 years (mean 31 years) (group A). These subjects were known to be consistently slow absorbers of paracetamol (Prescott and Nimmo, 1971). No other drugs were being taken at the time of investigation. In addition, the effect of propantheline on the kinetics of paracetamol absorption and gastric emptying was investigated in six convalescent hospital patients aged from 22 to 80 years (mean 56 years) (group B). Informed consent was obtained. None had undergone gastrointestinal surgery, and there was no clinical evidence of renal, hepatic, gastrointestinal, or cardiac disease. All other drugs were withheld during the period of investigation.

\section{PARACETAMOL ABSORPTION}

Group A.-After an overnight fast each healthy volunteer ingested $1.5 \mathrm{~g}$ of paracetamol (as three Panadol tablets) with $50 \mathrm{ml}$ of water. The test was repeated not less than one week later, but on this occasion $10 \mathrm{mg}$ of metoclopramide was injected intravenously at the same time as the paracetamol was taken.

Group B.-Simultaneous measurements of gastric emptying rate and paracetamol absorption were made in the patients. After an overnight fast $1.5 \mathrm{~g}$ of paracetamol (Panadol) was taken by mouth with $400 \mathrm{ml}$ of water containing 200 microcuries of $131 m$ In DTPA chelate. Gastric emptying rate was measured by sequential scintiscanning and the result expressed as a half time ( $t \frac{1}{2}$ ) (Heading et al., 1971). At least 48 hours later the whole procedure was repeated 15 minutes after intravenous injection of $30 \mathrm{mg}$ of propantheline. One patient received paracetamol alone and on subsequent occasions was given paracetamol with propantheline and paracetamol with metoclopramide.

Fluids were withheld for two hours after ingestion of paracetamol and tobacco and food were not allowed for four hours. 